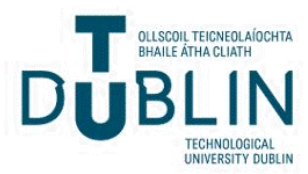

Technological University Dublin

ARROW@TU Dublin

2014-6

\section{Geographic Information System-based tools in environmental management}

\author{
Zeinab Bedri \\ Technological University Dublin, zeinab.bedri@tudublin.ie \\ Michael Bruen \\ University College Dublin, michael.bruen@ucd.ie
}

Follow this and additional works at: https://arrow.tudublin.ie/engschcivart

Part of the Civil Engineering Commons, and the Environmental Engineering Commons

\section{Recommended Citation}

Bedri, Z. \& Bruen, M. (2014)Geographic Information System-based tools in environmental management. International Journal of Environmental Studies, Vol. 71, No. 4, pp 526-533. doi.org/10.1080/ 00207233.2014.90801

This Article is brought to you for free and open access by the School of Civil and Structural Engineering at ARROW@TU Dublin. It has been accepted for inclusion in Articles by an authorized administrator of ARROW@TU Dublin. For more information, please contact arrow.admin@tudublin.ie, aisling.coyne@tudublin.ie, gerard.connolly@tudublin.ie.

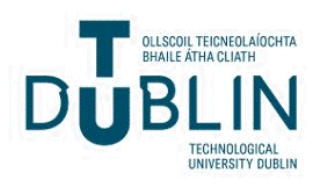




\section{PROOF COVER SHEET}

Author(s): Michael Bruen

Article title: Geographic Information System-based tools in environmental management

Article no: GENV 908014

Enclosures: 1) Query sheet

2) Article proofs

Dear Author,

1. Please check these proofs carefully. It is the responsibility of the corresponding author to check these and approve or amend them. A second proof is not normally provided. Taylor \& Francis cannot be held responsible for uncorrected errors, even if introduced during the production process. Once your corrections have been added to the article, it will be considered ready for publication.

Please limit changes at this stage to the correction of errors. You should not make trivial changes, improve prose style, add new material, or delete existing material at this stage. You may be charged if your corrections are excessive (we would not expect corrections to exceed 30 changes).

For detailed guidance on how to check your proofs, please paste this address into a new browser window: http://journalauthors.tandf.co.uk/production/checkingproofs.asp

Your PDF proof file has been enabled so that you can comment on the proof directly using Adobe Acrobat. If you wish to do this, please save the file to your hard disk first. For further information on marking corrections using Acrobat, please paste this address into a new browser window: http:// journalauthors.tandf.co.uk/production/acrobat.asp

2. Please review the table of contributors below and confirm that the first and last names are structured correctly and that the authors are listed in the correct order of contribution. This check is to ensure that your name will appear correctly online and when the article is indexed.

\begin{tabular}{|c|c|c|c|c|}
\hline Sequence & Prefix & Given name(s) & Surname & Suffix \\
\hline 1 & & Zeinab & Bedri & \\
2 & & Michael & Bruen & \\
& & & & \\
\hline
\end{tabular}


Queries are marked in the margins of the proofs, and you can also click the hyperlinks below.

\section{AUTHOR QUERIES}

\section{General points:}

1. Permissions: You have warranted that you have secured the necessary written permission from the appropriate copyright owner for the reproduction of any text, illustration, or other material in your article. Please see http://journalauthors.tandf.co.uk/permissions/usingThirdPartyMaterial.asp.

2. Third-party content: If there is third-party content in your article, please check that the rightsholder details for re-use are shown correctly.

3. Affiliation: The corresponding author is responsible for ensuring that address and email details are correct for all the co-authors. Affiliations given in the article should be the affiliation at the time the research was conducted. Please see http://journalauthors.tandf.co.uk/preparation/writing.asp.

4. Funding: Was your research for this article funded by a funding agency? If so, please insert 'This work was supported by <insert the name of the funding agency in full >', followed by the grant number in square brackets '[grant number $\mathrm{xxxx}$ ]'.

5. Supplemental data and underlying research materials: Do you wish to include the location of the underlying research materials (e.g. data, samples or models) for your article? If so, please insert this sentence before the reference section: 'The underlying research materials for this article can be accessed at $<$ full link $>$ / description of location [author to complete]'. If your article includes supplemental data, the link will also be provided in this paragraph. See $<\mathrm{http}: / /$ journalauthors.tandf.co.uk/preparation/multimedia.asp $>$ for further explanation of supplemental data and underlying research materials.

6. The CrossRef database (www.crossref.org/) has been used to validate the references. Mismatches will have resulted in a query.

\begin{tabular}{|c|c|}
\hline AQ1 & $\begin{array}{l}\text { The title has been modified to make it more clear and effective. Please confirm that } \\
\text { this is OK. }\end{array}$ \\
\hline AQ2 & Please check whether this shortened title is correct. \\
\hline AQ3 & $\begin{array}{l}\text { Please check the clarity of the sentence 'BASINS ... others.' and correct if neces- } \\
\text { sary. }\end{array}$ \\
\hline AQ4 & $\begin{array}{l}\text { Please check the edits made in the sentence 'other ... system.' and correct if neces- } \\
\text { sary. }\end{array}$ \\
\hline AQ5 & Please provide missing city for Refs. $[1,6]$ in the references list entry. \\
\hline AQ6 & $\begin{array}{l}\text { As per journal style, "et al." is not used in the references list. Please provide the } \\
\text { relevant author names in order to complete the Ref. [11]. }\end{array}$ \\
\hline
\end{tabular}




\section{How to make corrections to your proofs using Adobe Acrobat/Reader}

Taylor \& Francis offers you a choice of options to help you make corrections to your proofs. Your PDF proof file has been enabled so that you can edit the proof directly using Adobe Acrobat/Reader. This is the simplest and best way for you to ensure that your corrections will be incorporated. If you wish to do this, please follow these instructions:

1. Save the file to your hard disk.

2. Check which version of Adobe Acrobat/Reader you have on your computer. You can do this by clicking on the "Help" tab, and then "About".

If Adobe Reader is not installed, you can get the latest version free from http:/get.adobe.com/ reader/.

3. If you have Adobe Acrobat/Reader 10 or a later version, click on the "Comment" link at the righthand side to view the Comments pane.

4. You can then select any text and mark it up for deletion or replacement, or insert new text as needed. Please note that these will clearly be displayed in the Comments pane and secondary annotation is not needed to draw attention to your corrections. If you need to include new sections of text, it is also possible to add a comment to the proofs. To do this, use the Sticky Note tool in the task bar. Please also see our FAQs here: http://journalauthors.tandf.co.uk/production/index.asp.

5. Make sure that you save the file when you close the document before uploading it to CATS using the "Upload File" button on the online correction form. If you have more than one file, please zip them together and then upload the zip file.

If you prefer, you can make your corrections using the CATS online correction form.

\section{Troubleshooting}

Acrobat help: http://helpx.adobe.com/acrobat.html

Reader help: http://helpx.adobe.com/reader.html

Please note that full user guides for earlier versions of these programs are available from the Adobe Help pages by clicking on the link "Previous versions" under the "Help and tutorials" heading from the relevant link above. Commenting functionality is available from Adobe Reader 8.0 onwards and from Adobe Acrobat 7.0 onwards.

Firefox users: Firefox's inbuilt PDF Viewer is set to the default; please see the following for instructions on how to use this and download the PDF to your hard drive: http://support.mozilla.org/en-US/kb/ view-pdf-files-firefox-without-downloading-them\#w_using-a-pdf-reader-plugin 


\title{
Geographic Information System-based tools in environmental management
}

\author{
ZEINAB BEDRI AND MICHAEL BRUEN*
}

UCD Dooge Centre for Water Resources Research, School of Civil, Structural and Environmental Engineering, University College Dublin, Newstead Building, Belfield, Dublin 4, Ireland

\begin{abstract}
The authors reviewed existing modelling platforms as part of a large study of water and pollution pathways through catchments in Ireland (Irish EPA Pathways project). Worldwide, work on producing catchment management tools (CMTs) has been underway for some time and some of the tools identified here date from as early as 1989 . Some of the management problems and model conceptualisations have not changed very much but now there is a stronger emphasis on water quality and more concern about a wider range of contaminants. What has changed substantially is the use of Geographical Information System and Graphical Windows interfaces as technologies supporting a wider practical use of these tools. This review of existing CMTs identified three systems which would be candidates if a CMT had to be deployed immediately in Ireland. All have a rigid catchment model structure and lack the flexibility to include any new scientific information or flow-path conceptualisation that may emerge. The same modelling structure is used for all parts of the catchment, with spatial variation represented by parameter variation only and not variation in model structure. They also have rigid graphical user interfaces which cannot be tailored to match any specific requirements that may emerge from the pathways end-user workshops. Thus a CMT with a more flexible and accessible modelling structure is required if the results of current research are to be incorporated.
\end{abstract}

Keywords: GIS; Environmental management; Hydrological pathways

\section{Introduction}

A catchment management tool (CMT) is a computer programme used to design or select appropriate options for managing water at catchment scale. Some tools may focus on water resources management, mainly relating to water quantities and distribution and others may be concerned also with the management of water quality. Because spatial variation is important in catchment information and behaviour, most CMTs require spatial information and thus are associated with a Geographical Information System (GIS); and because of the complexity of catchment behaviour, most CMTs require the use of a catchment model. There are dozens of such models, covering a wide range of scales and processes. The choice must be determined by the range of issues and contaminants to be addressed by the CMT and by the spatial and temporal scales at which detailed information is required by the decision-maker. An inappropriate choice can invalidate the output from the CMT.

Ideally, the choice of catchment modelling approach determines the data requirements. Data may be spatially distributed (e.g. maps) or may change with time (time-series) and

*Corresponding author. Email: michael.bruen@ucd.i.e 
both kinds must be managed within the framework of the CMT. Other forms of data include parameter sets, constraint sets and point information. All such data must be carefully managed and therefore a GIS program linked to a formal database system (DBS) is generally used. The use of existing GIS and DBS systems may have the disadvantage of constraining flexibility in the design of the CMT, but has the distinct advantage of proven technology with easier communication in standard data formats with outside data sources.

This paper reviews the state of the art in relation to practical CMTs for managing water quality with the objective to assist water quality managers in making informed decisions in a practical context and it concentrates on (i) CMTs that address water quality management issues and (ii) CMTs for use by scientifically or technically trained people responsible for the design, implementation or management of measures for addressing the quality of natural waters.

\section{GIS support and links}

Geographic Information Systems are indispensable for hydrological modelling and nutrient management in agricultural catchments because they use the capabilities of modern, highspeed computers to store, manipulate and display large amounts of environmental data in a spatial format. A range of reliable GIS tools are widely available nowadays. Some are free e.g. QGIS, GRASS, PCRaster, MapGuide, Mapwindow and OpenMap, while others are propriety/commercial packages and must be purchased or licensed, e.g. ArcGIS (ArcView and ArcInfo) and MapInfo. Hydrological (catchment) modelling tools are frequently linked with GIS systems. There are four ways to link GIS with catchment models [1].

(1) Isolated coupling, in which the hydrological modelling and GIS systems reside on different hardware platforms, and data transfer is offline. This method is rarely used although isolated systems are the easiest to set up and require the least level of programming knowledge and experience. On the other hand, they are generally the least useful, because of the need to transfer data offline. An example of such a model is WATFLOOD/SPL9 [2-4].

(2) Loose coupling, with online data transfer between software components through data files using special linking programs, or through a common data store. Loose coupling uses the GIS as an aid in developing the input data files for the model. These preliminary input files can be modified in order to produce complete input files in the format required by the model. Thus, both the model and the GIS system can be used without any modification [5]. An example of such a type is TOPMODEL [6].

(3) Tight coupling, with the two systems communicating interactively with each other. A special interfacing program communicates between the GIS and the hydrological model, and serves as a control program issuing commands both to the GIS and the model. Output from the GIS is converted into the proper input format for the model and then read into the model. Output from the model may likewise be converted to a GIS format and then displayed by the GIS. All these operations are controlled by the interface program [5] and, typically, all user interactions are through the GIS interface. Examples are ANSWERS and AGNPS.

(4) Full integration, which does not require a linking program, but the GIS and models share a common data store and user-interface which come up as one software 
product. Typically, with this method, the hydrological model is coded within the built-in programming or macro-language of the GIS and has direct access to the facilities and functions of the GIS. In a fully integrated system, the model is embedded as a component in the host GIS application [7] and therefore modelling is managed entirely within the GIS. Examples of fully integrated catchment models are SWAT, AVGWLF and HSPF (MAPWINDOWS).

The degree of relationship between a model and a GIS has an impact on the reliability and ease of use of the system. Well-integrated systems work as a coherent whole, allowing the experienced user some access to intermediate results and the ability to use his or her own measurements or model outputs where the tool requires inputs, and still afford flexibility for modifying the modelling scenario [7].

\section{Most commonly encountered catchment management systems}

A literature search for commonly encountered catchment management systems yielded 14 systems for the current review (table 1). Most of these operate on Windows-based PCs, except NELUP which runs on a UNIX operating system. These systems are evaluated and compared in terms of their flexibility, modelling and operating capabilities, and their demand on input and output data:

\subsection{Flow modelling capabilities}

All reviewed catchment systems have the ability to simulate flow in catchments using hydrological models except for two systems, CMSS and Realta. CMSS is intended to provide a 'first-cut' analysis of the major contributors of sediment or nutrients from a catchment as a result of changes in land-use and/or land-management practices [8]. Its

Table 1. Reviewed catchment modelling systems.

\begin{tabular}{|c|c|}
\hline System & Developer \\
\hline BASINS & US EPA \\
\hline MIKEBasin & Danish Hydraulic Institute (DHI) \\
\hline WMS & Aquaveo (http://www.aquaveo.com/wms) \\
\hline MONERIS & Institute of Freshwater Ecology and Inland Fisheries, Leibniz, Germany \\
\hline NELUP & $\begin{array}{l}\text { The Macaulay Land Use Research Institute, Craigiebuckler, Aberdeen, UK under the } \\
\text { NERC-ESRC Land-Use Programme }\end{array}$ \\
\hline NLCAT & Integrated water and catchment management, Alterra, Wageningen UR, Netherlands \\
\hline TRK & Swedish Environmental Research Institute and SMHI, Sweden \\
\hline $\begin{array}{l}\text { TCM- } \\
\text { Manager }\end{array}$ & Martens and Associates Pty Ltd., Australia \\
\hline WAMADSS & $\begin{array}{l}\text { Centre for Agricultural, Resource and Environmental Systems (CARES) at University } \\
\text { of Missouri-Columbia, USA }\end{array}$ \\
\hline CMSS & CSIRO Land and Water, Canberra \\
\hline SOBEK & Deltares and Delft Hydraulics \\
\hline Realta & Kirk McClure Morton, Belfast, Northern Ireland \\
\hline EveNFlow & Agricultual and environmental consultancy ADAS, UK \\
\hline WEAP & US branch of the Stockholm Environment Institute, Boston, Massachusetts, USA \\
\hline
\end{tabular}


main limitation is that it is restricted to long-term average behaviour, because it does not consider hydrology or any time-variant components. Realta identifies potential agricultural risk areas at a River Basin District level and quantifies phosphorous export rates from the River Basin District and its sub-catchments. It does not use dynamic rainfall-runoff catchment modelling and does not include in-stream and/or lake retention of pollutants.

Some of the reviewed catchment systems offer a large range of hydrological models (table 2) of varying complexity (e.g. empirical, semi-empirical or physically based). WMS offers the largest number of models (around 15 hydrological and hydraulic models) while some others offer two to three models (e.g. BASINS, MIKEBASIN, NELUP and TRK).

\subsection{Water quality modelling capabilities}

15 With the exception of WMS, all reviewed systems include a water quality component. The minimum water quality variables included in these systems are nitrogen and phosphorus (e.g. MONERIS, NELUP, NL-CAT, TRK, REALTA and CMSS). A few models have the capacity to simulate a wider suite of water quality variables. BASINS can simulate pesticides and bacteria, while MIKEBASIN offers bacteria, oxygen, BOD among others. SOBEK allows for the simulation of a wide range of water quality variables including bacteria, algae, silica and heavy metals.

Despite the significant role of sediments in the transport of nutrients (Nitrogen and Phosphorus) as highlighted by a large number of studies $[9,10]$, not many of the reviewed systems include sediment transport in their processes.

\subsection{Required data}

Table 3 shows that the minimum information required by most systems reviewed here is data on the topography, river network, land cover, soils, in addition to information about the pollutant loads. Somewhat surprisingly, independent groundwater data (e.g. water levels and contaminant concentrations) are rarely used. Of the systems reviewed here, BASINS, MIKEBASIN and SOBEK are the most demanding; and CMSS is the system that appears to require the least amount of data.

\subsection{Management options}

The systems were also compared in terms of their suitability for assessing impacts of (i) land-use changes, (ii) nutrient management options and (iii) water protection measures as a tool to enable catchment managers and planners to examine the impact of land-use changes and management options on the water quality in catchments. Only eight of the reviewed systems (BASINS, MIKEBASIN, NELUP, NL-CAT, TRK, SOBEK, EveNFlow and WEAP) have the ability to assess all three environmental measures. MONERIS, TCM-Manager and CMSS are suitable for assessing land-use changes and management options, but not all changes to water measures.

\subsection{GIS support}

Most of the reviewed catchment management systems employ GIS as a tool for data handling and visualisation (table 2). The mostly used GIS software in these systems is 
Geographic Information System

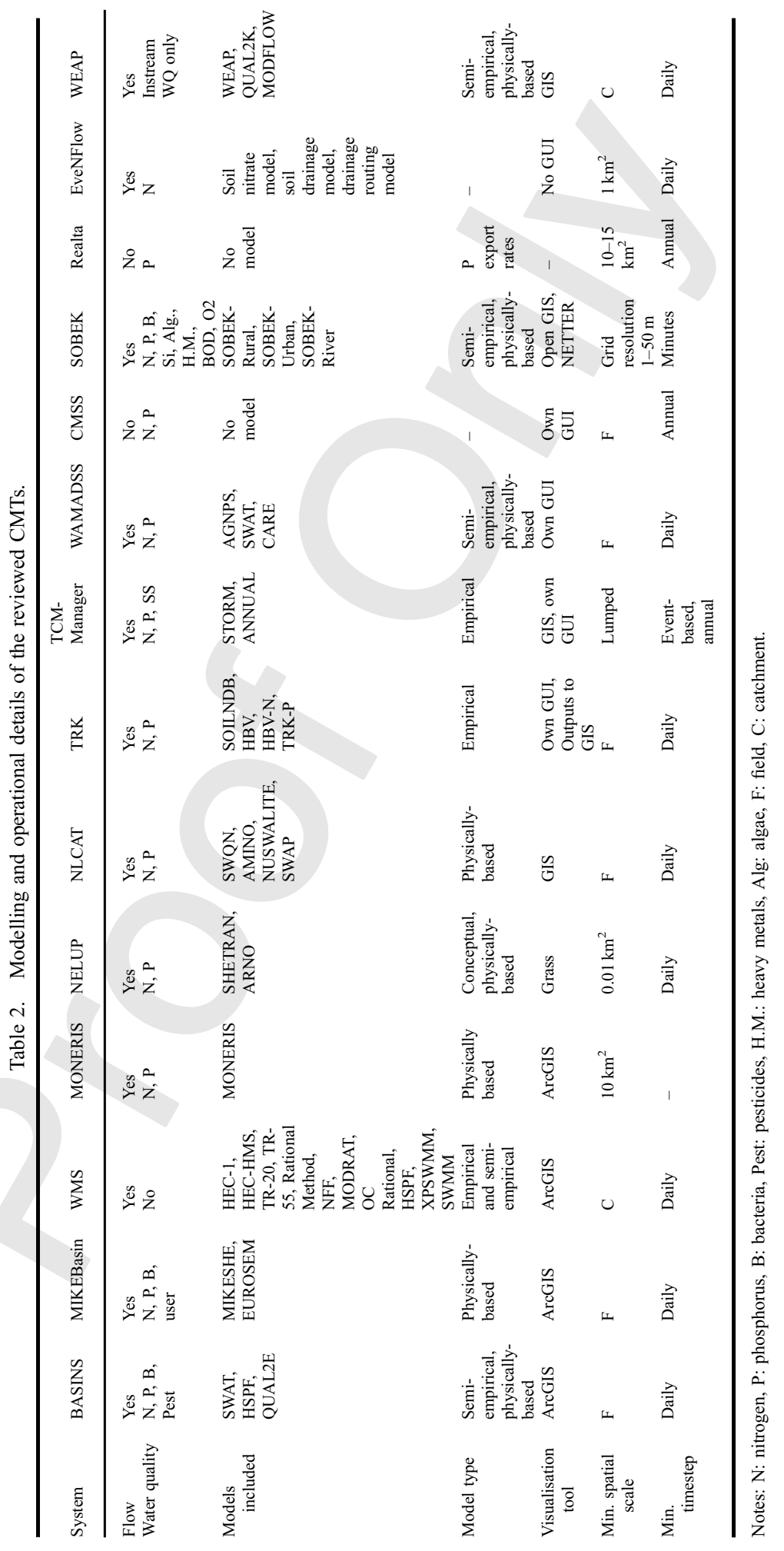




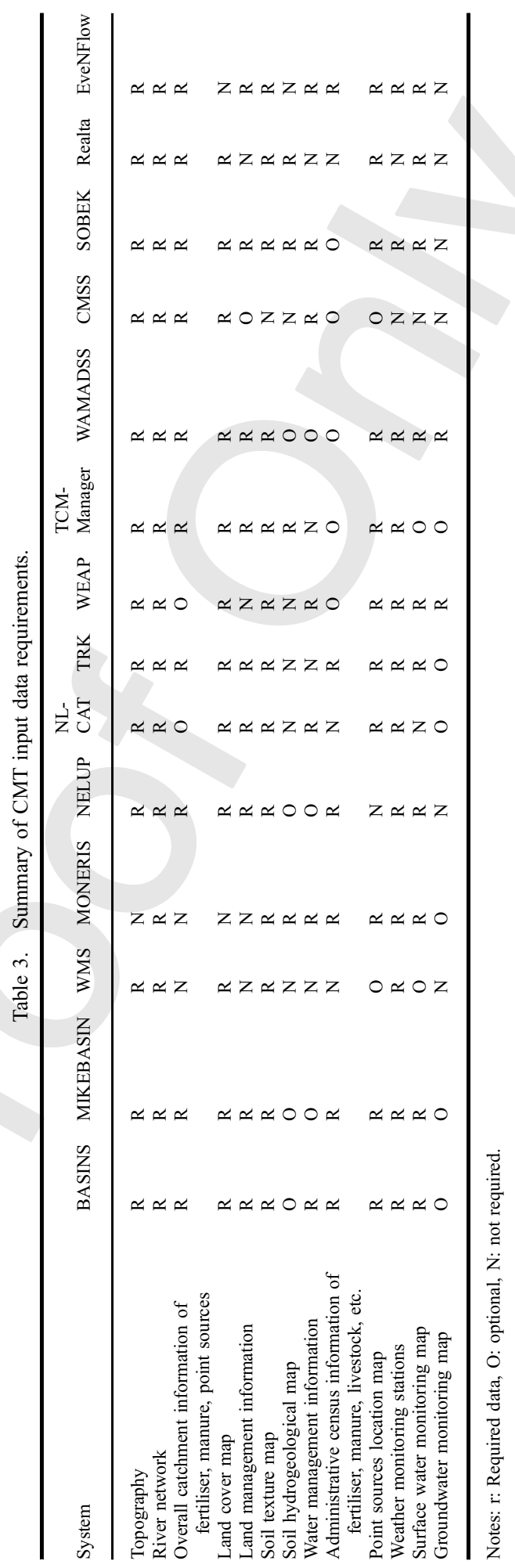


ARCGIS (e.g. MIKEBASIN, WMS and MONERIS). Other GIS softwares used include the UNIX-based Grass GIS used in the NELUP system and Open GIS NETTER used in the SOBEK modelling system. A few of these systems have their own graphical interfaces e.g. CMSS and EveNFLOW. TCM-Manager has its own graphical interface but produces outputs that can be manipulated by standard GIS packages.

\section{Comparison and evaluation of existing CMTs}

Table 2 summarises the capabilities of the CMTs reviewed here and lists some of their operating characteristics. Table 3 summarises their input data requirements. All except one (WMS) have some water quality modelling capabilities; but some are limited to sediment, $\mathrm{N}$ and $\mathrm{P}$. Those that can simulate more contaminants than sediment, $\mathrm{N}$ and $\mathrm{P}$ are BASINS, MIKEBASIN and SOBEK. All three can simulate bacteria and other contaminants and could be candidates as a suitable CMT. All three come from organisations with extensive experience of hydraulic and water quality modelling; but each has some individual disadvantages;

(i) BASINS was developed for use in the USA and is written to interface easily with USA data sources. Nevertheless, it is possible to edit Irish data sources to comply with the input formats required by BASINS [11]. This procedure must be done individually for each catchment and might have to be redone each time a new version of BASINS is issued. Although this is not an ideal solution, an experienced GIS user could be trained to perform this step for a catchment manager. To integrate new pathways into the model would require modifying the FORTRAN source code. This procedure has been done in the UCD Dooge Centre for Water Resources Research for some of the models (e.g. SWAT and HSPF), but is difficult and requires a specialist hydrological modeller with computer programming experience.

(ii) MIKEBASIN is based on the MIKE SHE hydrological model. This is a distributed physically based model and is one of the most detailed and complex models available. Since it is a commercial model, the source code is not normally made available to users, who cannot easily incorporate additional pathways or modifications of existing pathways. Such improvements could be incorporated by the model developer in its upgrade cycle, but this would be subject to negotiation between model users and developer. Specific licences would be required for each user. The MIKE SHE approach (as implemented in SHETRAN) has been tested (and compared to two other hydrological models) in some Irish catchments for modelling phosphorus (EPA LS-2.2.2) and its performance was not the best of the models evaluated.

(iii) SOBEK is used in the Netherlands and concentrates more on the process within channels with less focus on modelling processes within the catchment.

Although any of these three models could contribute significantly to catchment management activities, all seem to require a high degree of expertise which militates against their widespread use in Ireland as a CMT. In addition, they focus mainly on surface water flows. Because of this, a CMT was desired that (1) is easier to use by catchment managers and (2) had an increased focus on sub-surface contaminant pathways, so that their influence could be studied in detail. 


\section{Conclusions}

As part of the Irish EPA Pathways project, a literature review of commonly encountered catchment management systems was conducted. The search yielded 14 systems of varying complexity. These were compared in terms of their modelling capabilities, abilities to help decision-makers to examine the impact of land-use changes and management options on the water quality in catchments, and the use of GIS for data handling and visualisation.

Three systems were identified as potential candidates if a CMT had to be deployed immediately in Ireland, namely BASINS, MIKEBASIN and SOBEK. All three come from organisations with extensive experience of hydraulic and water quality modelling. But there are some common disadvantages. All are based on a fixed catchment model structure making it difficult to include any new flow-path or process conceptualisations that may emerge. The same modelling structure is used for all parts of the catchment, with spatial variation represented by parameter variation only and not variation in model structure. They also have fixed graphical user interfaces which cannot be tailored to match any specific implementation requirements that emerge from end-user workshops. Most are intended for use by a specialised modeller rather than by an interested end user. Thus a CMT with a more flexible and accessible modelling structure, particularly of sub-surface pathways, is required if a wider use by a variety of different end users is desired and if the results of current (or future) research are to be incorporated.

\section{Acknowledgements}

The work reported here was supported by the Irish EPA under the STRIVE programme as contract 2007-W-CD-1-S1 which is a project of partners from University College Dublin, Queen's University Belfast and Trinity College Dublin.

\section{References}

[1] Nyerges, T.L., 1992, Coupling GIS and spatial analytic models. In: E. Bresnahan, D. Corwin and D.J. Cowan (Eds.) 5th International Symposium on Spatial Data Handling, International Geographical Union Commission on GIS, vol. 2, pp. 534-543.

[2] Cranmer, A., Kouwen, N. and Mousavi, S.F., 2001, Proving WATFLOOD: Modelling the non-linearities of hydrologic response to storm intensities. Canadian Journal of Civil Engineering, 28(5), 837-855.

[3] León, L.F., Soulis, E.D., Kouwen, N. and Farquhar, G.J., 2002, Modeling diffuse pollution with a distributed approach. Journal of Water Science and Technology, IWA, 45(9), 149-156.

[4] Stadnyk, T., Amour, N., Kouwen, N., Edwards, T.W.D., Pietroniro, A. and Gibson, J.J., 2005, A groundwater separation study in boreal wetland terrain: The WATFLOOD hydrological model compared with stable isotope tracers. Isotopes in Environmental and Health Studies, 41(1), 49-68.

[5] Nasr, A.E., 2004, Modelling of phosphorus loss from land to water: A comparison of SWAT, HSPF and SHETRAN/GOPC for three Irish catchments. PhD Thesis, University College Dublin, National University of Ireland.

[6] Beven, K., Lamb, R., Quinn, P., Romanowicz, R. and Freer, J., 1995, TOPMODEL. In: V. Singh (Ed.) Computer Models of Watershed Hydrology (Water Resource Publications), pp. 1-43.

[7] Pullar, D. and Springer, D., 2000, Towards integrating GIS and catchment models. Environmental Modelling \& Software, 15, 451-459.

[8] Davis, J.R. and Farley, T.F.N., 1997, CMSS: Policy analysis software for catchment managers. Environmental Modelling \& Software, 12(2-3), 197-210.

[9] Kerr, J.G., Burford, M.A., Olley, J.M., Bunn, S.E. and Udy, J., 2011, Examining the link between terrestrial and aquatic phosphorus speciation in a subtropical catchment: The role of selective erosion and transport of fine sediments during storm events. Water Research, 45(11), 3331-3340.

[10] Bechmann, M., Stålnacke, P., Kværnø, S., Eggestad, H.O. and Øygarden, L., 2009, Integrated tool for risk assessment in agricultural management of soil erosion and losses of phosphorus and nitrogen. Science of The Total Environment, 407(2), 749-759.

[11] Nasr, A., Bruen, M., et al., 2007, A comparison of SWAT, HSPF and SHETRAN/GOPC for modelling phosphorus export from three catchments in Ireland. Water Research, 41(5), 1065-1073. 